\title{
THEORY OF LARGEST VALUES APPLIED TO EARTHQUAKE MAGNITUDES
}

\author{
John M. Nordqulst
}

(Contribution No. 375, Balch Graduate School of the Geological Sciences, California Institute of Technology, Pasadena, Callfornia)

The theory of largest values [see 1, 2, of "References" at end of paper] requiring data on only the largest event in each of a number of equal time-intervals, recommended itself to the author as a possible way of describing the earthquake activity of a region. A preliminary analysis using the calendar month as the interval having demonstrated the applicabllity of the theory in this fleld, the author has investigated the feasibility of using still shorter intervals [3]. In the present paper the interval used is one-third of a month--the first day through the tenth, the eleventh through the twentieth, and the twenty-first to the end of the month. This interval therefore corresponds to that of one year used in flood-analyses. A compensating change has been made in the return-period scale (Fig. 2). Incomplete results of further analysis indicate that it is feasible to use a time-interval as short as five days.

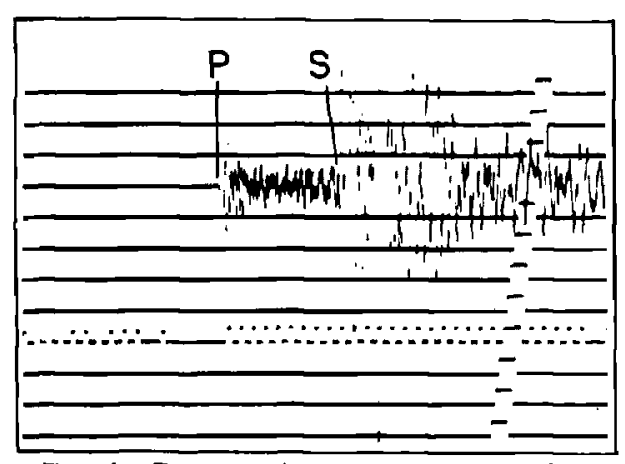

Fig, 1--Representative seismogram for concept of earthquake-magnitude

The concept of earthquake magnitude $[4,5,6]$ is based on the largest amplitude in a seismogram recorded by a Wood-Anderson torsion seismometer (free period $0.8 \mathrm{sec}$, static magnification 2800 , damping nearly critical). A representative record is shown in Figure 1, which is a typical record of an earthquake of magnitude $4-1 / 2$ originating 48 miles from the recorder. The up-and-down displacement of the horizontal line represents the north-and-south motion of the ground at the instrument, magnified about 2500 times. The breaks in the line near the bottom of the Figure are the $1 \mathrm{~m}$ pulses, one second apart, of part of a radio timesignal. Recording speed of the original record (reproduction is reduced to about $2 / 3$ of original) was $1 \mathrm{~mm} / \mathrm{sec}$. This instrument is standard at the Selsmological Laboratory in Pasadena, Callfornia, and at six of its auxiliary stations. The scale of magnitudes is logarithmic, a tenfold increase in the amplitude corresponding to an increase of one in the magnitude. It is made independent of the distance from source to instrument through the use of an empirically determined table of recorded amplitude as a function of distance. So far, its application has been limited to earthquakes of "normal" focal depth (15 to $40 \mathrm{~km}$ ). After cor rections have been made for the idiosyncrasles of individual selsmographs and stations, the magnitudes determined for a single earthquake in the Southern California Region usually show a range of not more than one-half unit on the scale. The range of magnitudes obtained for distant shocks may be somewhat larger. In routine reports the average magnitude, as determined from all avallable instruments, is given to the nearest one-half unit.

Under especially favorable conditions, earthquakes of magnitudes 1-1/2 have been reported felt near the epicenter; shocks of magnitude 3 are usually felt; those of magnitude 4-1/2 are capable of.causing slight damage near the eplcenter; while major earthquakes, capable of causing extensive damage, range from magnitude 7 to magnitude $8-1 / 2$. There is no good evidence that any historical earthquake has had a magnitude much over $8-1 / 2$.

The materials used Include (a) a list [7] of all "normal" earthquakes of magnitude 7-3/4 and over, for the years 1904-38, (b) a list [7] of all "normal" earthquakes of magnitude 7 and over from January, 1926, through March, 1934, (c) a list of the earthquakes in a reglon of about 100,000 square miles, including most of southern California and part of Lower California, from January, 1934, through September, 1942, and (d) a selection from (c) of the earthquakes in a region of about 


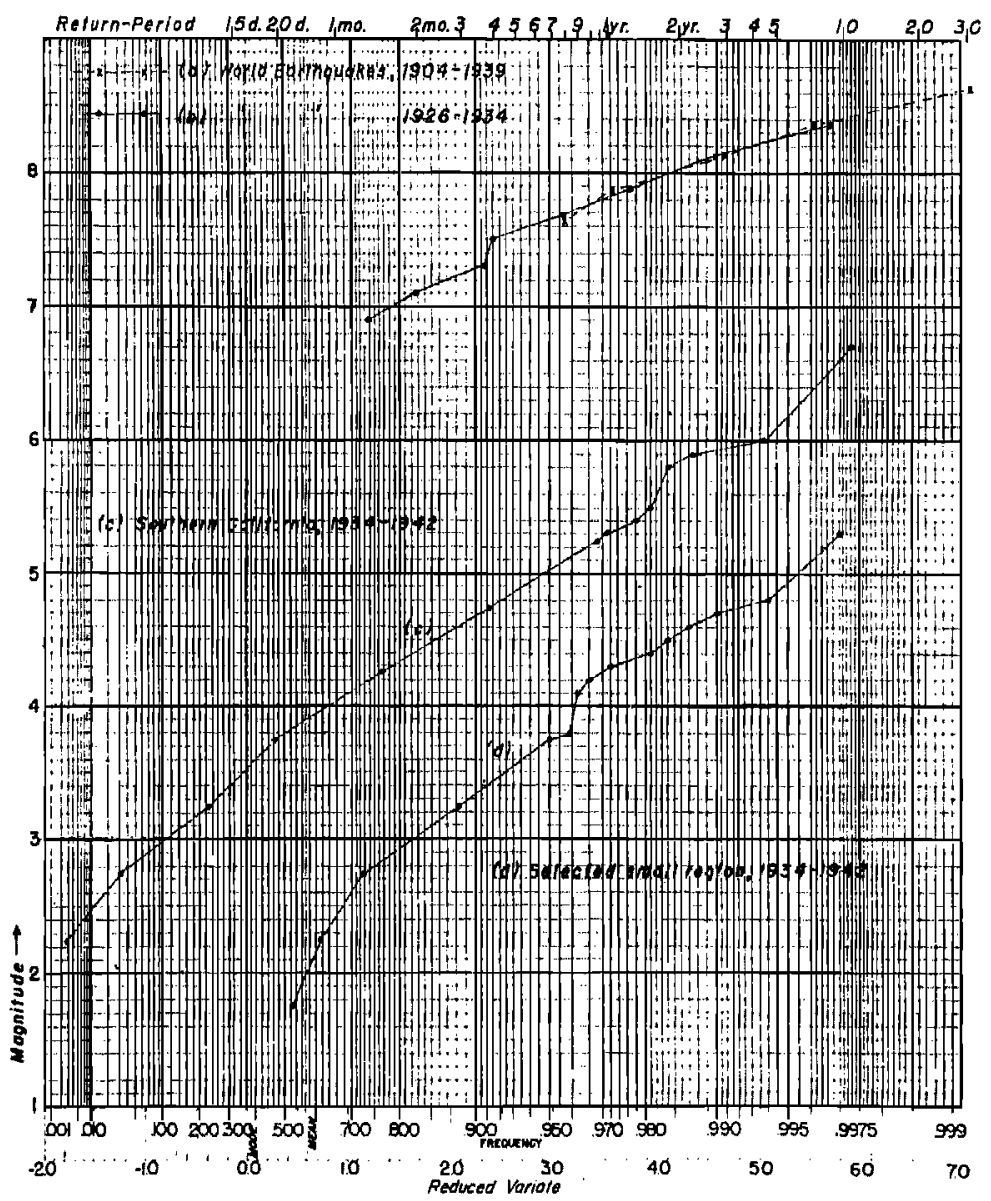

Fig. 2--Observed distribution of magnitudes of great earthquakes and Gumbel's theory of largest values

1300 square mlles, east of Los Angeles. Lists (c) and (d) have been excerpted by the author from the "Local report" of the Selsmological Laboratory in Pasadena.

Table 1 (parts a, b, c, and d) shows the reduction [8] of the data from the corresponding lists to the varlable $F\left(\tilde{x}_{m}\right)$ plotted on GUMBEL'S probabllity-paper in Figure 2.

It will be seen from Figure 2 that all the points plotted for the earthquakes of the entire world can be represented fairly well by a straight line. The same is true for the plotted points for each smaller region separately, indicating that in each case the observed distribution of the magnitudes of the largest earthquakes is in good agreement with the theory of largest values even when so short a time-interval as ten days is used as a unit.

\section{References}

[1] E. J. GUMBEL, Statistical control-curves for flood-discharges, Trans. Amer. Geophys. Union, pp. 489-509, 1842.

[2] E. J. GUMBEL, On the plotting of flood-discharges, Trans. Amer. Geophys. Union, pp. 699-716, 1843. 
Table 1-- - Large earthquakes

\begin{tabular}{|c|c|c|c|c|c|c|c|c|c|}
\hline $\mathbf{M}$ & $\begin{array}{l}\text { Upper } \\
\text { class- } \\
\text { limit }\end{array}$ & No. & $\begin{array}{l}\text { m for upper } \\
\text { class-limit }\end{array}$ & $\mathbf{F}\left(\tilde{\mathbf{x}}_{\mathbf{m}}\right)$ & $\mathbf{M}$ & $\begin{array}{l}\text { Upper } \\
\text { class- } \\
\text { limit }\end{array}$ & No. & $\begin{array}{l}m \text { for upper } \\
\text { class-limit }\end{array}$ & $\mathbf{F}\left(\tilde{\mathbf{x}}_{\mathbf{m}}\right)$ \\
\hline \multicolumn{5}{|c|}{ (a) Very large earthquakes of the world, $1904-42$} & \multicolumn{5}{|c|}{ (c) Concluded } \\
\hline $71 / 2$ & 7.62 & 19 & 1242 & .9576 & 5.4 & & 2 & 309 & .978 \\
\hline $73 / 4$ & 7.87 & 19 & 126 & .9722 & & & 1 & 310 & .981 \\
\hline & 8.12 & 24 & 1285 & .9908 & 5.8 & & 1 & 311 & .984 \\
\hline $81 / 4$ & 8.37 & 7 & $12 \theta 2$ & .9961 & 5.9 & & 1 & 312 & .9873 \\
\hline $81 / 2$ & 8.62 & 4 & 1296 & .9992 & 6.0 & & 2 & 314 & .9936 \\
\hline \multicolumn{5}{|c|}{ (b) Large earthquakes of the world, 1926-34 } & 6.7 & & 1 & 315 & .9968 \\
\hline 6.8 & 6.9 & & 220 & .738 & \multirow{2}{*}{\multicolumn{5}{|c|}{$\begin{array}{c}\text { (d) Earthquakes of small region in southern } \\
\text { Californta, } 1934-42\end{array}$}} \\
\hline 7.0 & 7.1 & 26 & 246 & .825 & & & & & \\
\hline 7.2 & 7.3 & 25 & 271 & .909 & $11 / 2$ & 1.75 & & 166 & .525 \\
\hline 7.4 & 7.5 & 10 & 281 & .913 & & 2.25 & 23 & & .598 \\
\hline 7.6 & 7.68 & 4 & 285 & .95 & $2 \cdot 1 / 2$ & 2.75 & 41 & 230 & .728 \\
\hline $73 / 4$ & 7.87 & 6 & 291 & .9765 & & 3.2 & 49 & 279 & .883 \\
\hline & 8.12 & 4 & 295 & .9899 & $31 / 2$ & 3.75 & 21 & 300 & .950 \\
\hline B $1 / 4$ & 8 & & & 0 & 3.8 & & 3 & 303 & .959 \\
\hline \multirow{9}{*}{$\begin{array}{l}\text { (c) Earth } \\
2 \\
21 / 2 \\
3 \\
31 / 2 \\
4 \\
41 / 2 \\
5 \\
5.3 \\
\end{array}$} & quakes 0 & uthe & California, & $1934-42$ & 4,1 & & 1 & 304 & .962 \\
\hline & 2.25 & 1 & 1 & .0026 & 4.2 & & 1 & 305 & .965 \\
\hline & 2.75 & 9 & 10 & .031 & 4.3 & & 2 & 307 & .972 \\
\hline & 3.25 & 61 & 71 & .22 & 4.4 & & 3 & 310 & .981 \\
\hline & 3.75 & 84 & 145 & 459 & 4.5 & & 1 & 311 & .984 \\
\hline & 4.25 & 96 & 241 & .763 & 4. & & 1 & 312 & .987 \\
\hline & & 47 & 288 & .9 & 4.7 & & 1 & 313 & .990 \\
\hline & 5.2 & 18 & 306 & .968 & 4 & & 1 & 31 & .994 \\
\hline & & 1 & 307 & .971 & 0.5 & & 1 & 315 & .997 \\
\hline
\end{tabular}

[3] B. GUTENBERG and C. F. RICHTER, Recent results of earthquake study in southern Callfornia, Trans. Amer. Geophys. Union, pp. 95-96, 1943.

[4] C. F. RICHTER, An instrumental earthquake magnitude scale, Bull. Seis. Soc. Amer., v. 25, pp. 1-32, 1935 .

[5] B. GUTENBERG and C. F. RICHTER, On selsmic waves (3d paper), Gerlands Beitr. Geophysik, v. 47 , pp. $73-131,1936$.

[6] B. GUTENBERG and C. F. RICHTER, Earthquake magnitude, intensity, energy, and acceleration, Bull. Sels. Soc. Amer., v. 32, pp. 163-191, 1942.

[7] B. GUTENBERG and C. F. RICHTER, Selsmicity of the Earth, Geol. Soc. Amer., Special Papers, No. 34, pp. 1-131, 1941.

[8] E. J. GUMBEL, Simplified plotting of statistical observations, Trans. Amer. Geophys. Union, pp. $69-82$, v. 26,1945 .

Seismological Laboratory, 220 N. San Rafael Avenue, Pasadena 2, California 